\title{
Steady and Unsteady Casingwall Flow Phenomena in a Single-Stage Low-Speed Compressor at Part-Load Conditions
}

\author{
H. Saathoff, A. Deppe, and U. Stark \\ Institute of Fluid Mechanics, Technical University Braunschweig, Germany
}

\author{
M. Rohdenburg, H. Rohkamm, D. Wulff, and G. Kosyna \\ Pfleiderer-Institute, Technical University Braunschweig, Germany
}

This article describes an investigation of the casingwall flow phenomena in a single-stage, axial-flow, low-speed compressor at part-load conditions, utilizing an oil-flow technique to visualize the boundary layer development and highfrequency sensors to measure ensemble-averaged velocity and flow-angle distributions as well as unsteady total pressure distributions. Representative results are shown and discussed. The results enable different sources of endwall blockage to be identified and changes with flow rate to be determined.

Keywords Casingwall boundary layer separation, Spill-forward, Stall inception, Tip clearance flow

Recent investigations (Saathoff, 2001; Saathoff and Stark, 2001) of the flow in a single-stage, low-speed, axial-flow compressor show (between maximum pressure rise and stall) the clearance vortex of the rotor to be enclosed in a separation bubble with circumferential separation and attachment lines on the inner casingwall. When this happens, the separation bubble, which already exists, begins to create substantial endwall blockage, resulting in a considerable reduction in effective freestream or core flow area. As a consequence the stator inlet flow and the stator through flow turn out to be highly different from what has been intended. This is one of the two topics about which this article presents initial results from an ongoing study of the flow in stators. With decreasing flow rate, the attachment line stays fixed at the trailing edge while the separation line moves upstream

Received 25 June 2002; accepted 1 July 2002.

Address correspondence to Dr. H. Saathoff, Technische Universitat Braunschweig, Institute fur Stromungsmechanik, Bienroder Weg 3, Braunschweig, 38106, Germany. E-mail: h.saathoff@tu-bs.de toward the leading edge. The last stable operating point is for a flow rate of $\varphi=0.41$ with the separation line close to the leading edge. Further throttling of the compressor leads to rotating stall, with the separation line jumping far in front of the rotor.

The second topic is the transient behavior of the rotor clearance flow at stall inception.

\section{EXPERIMENTAL FACILITIES AND PROCEDURES}

The compressor investigations were carried out on a singlestage, axial-flow, low-speed compressor designed at the Institute of Fluid Mechanics, Technical University Braunschweig, and tested at the Pfleiderer-Institute, also Technical University Braunschweig. The compressor has an outer diameter $D_{o}=$ $0.4 \mathrm{~m}$ and a hub-to-tip ratio $v=0.55$. The rotor comprises 16 and the stator 19 blades of the National Advisory Committee for Aeronautics (NACA) 65-series blade sections and the aerodynamic design is such as to give a free vortex flow for the following design parameters: (1) flow coefficient $\varphi=0.6$; (2) pressure rise coefficient $\psi=0.5$; and (3) rotational speed $n=4500 \mathrm{rpm}$. The rotor tip clearance to chord ratio is $s / l=3 \%$, with tip clearance $s=1.8 \mathrm{~mm}$ and chord $l=60 \mathrm{~mm}$. The stator has neither a tip nor a hub clearance. The rotor/stator gap is about $a=45 \mathrm{~mm}$ at the casing.

The stage was run at a constant speed and the air flow rate adjusted by means of a throttle and an auxiliary fan until the upstream axial velocity to produce the desired flow coefficient $\varphi$ (mean axial velocity divided by the rotor tip speed) was obtained. The velocities encountered in the stage are such that the flow may be regarded as being incompressible. The Reynolds number (Re) based on chord and relative inlet velocity at the rotor tip is $\operatorname{Re}=4.4 \cdot 10^{5}$ for the design flow conditions. The static pressure rise coefficient $\psi$ (static pressure rise divided by the dynamic pressure corresponding to the rotor tip speed) was evaluated using the static pressures measured on the casing about one chord upstream and three chords downstream from the 
compressor stage. The inlet flow was traversed with a constant temperature hot-wire anemometer at a traverse plane (r, $\Theta$-plane with $r$ in radial and $\Theta$ in circumferential direction) about $60 \%$ chord upstream of the rotor. The measured velocity distributions were used to determine the characteristics of the inlet boundary layer.

Oil flow pictures are photographs of specially prepared surfaces. In the present investigation they were produced for the inner surface of the compressor casing and for some of the stator blades, showing the surface shear stress lines which closely approximate the streamlines of the flow next to the surface. The oil flow pictures are time-mean portraits of the flow because of the well-known unsteadiness of the compressor flow. The analysis of the pictures should be regarded as preliminary.

Phase-locked velocity distributions downstream from the rotor were obtained using hot-wire probes. Assuming the radial velocity component to be generally small enough to be neglected, the remaining velocity components in axial and circumferential direction were measured by two calibrated single-sensor probes, simulating an X-type hot-wire probe. Both probes (one of them is shown in Figure 1) were arranged in a $z, \Theta$-plane with the hot-wires forming a 90 degree angle. The position of the $z, \Theta-$ plane was $\Delta z=29 \mathrm{~mm}$ downstream from the rotor tip, and the angular distance of the two probes was $\Delta \Theta=45^{\circ}$, that is, two pitches. Further adjustment of the probes was necessary in order to ensure that the difference in flow and wire direction was 45 degrees for both probes in order to achieve highest angle sensitivity. Temperature and density effects were taken into account. Data were acquired for the complete annulus between $r^{\prime}=1 \mathrm{~mm}$ (casing value $r^{\prime}=0$; see Figure 1) and $r^{\prime}=89 \mathrm{~mm}$ (hub value $r^{\prime}=90 \mathrm{~mm}$; see Figure 1 ) with decreasing $\Delta r^{\prime}$ toward hub and casing. The data recording was triggered by shaft encoder pulses, which were used in the data memory as an external time base. For the hot-wire measurements, 400 pulses per revolution were used, corresponding to an interval of $\Delta \Theta=0.9^{\circ}$

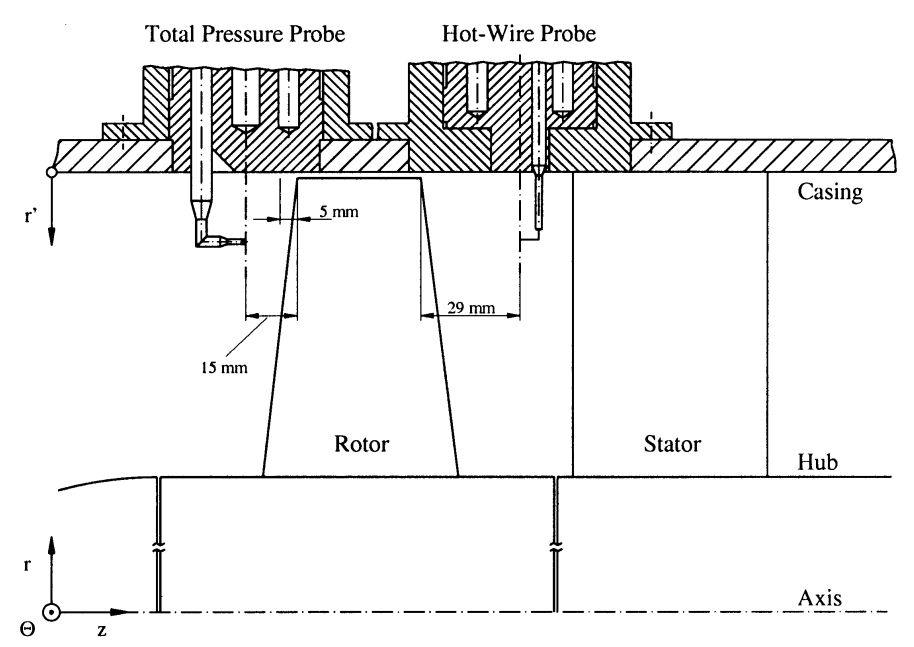

FIGURE 1

Setup of probes. in rotor coordinates or to 25 samples per blade passage. The use of an additional reference pulse ensured a clear relationship between recorded data and the rotor position.

Because the two hot-wire probes were located 45 degrees apart (which is equivalent to 50 pulses from the shaft encoder), the simultaneously recorded data of both probes were shifted by 50 counts relative to one rotor blade. During data reduction the data strings of both probes were then reshifted. This procedure led to sets of data that were taken at different positions in machine coordinates but at the same geometric position in rotor coordinates. Finally, corresponding values of the sample records at all radial probe positions were arithmetically averaged for 80 rotor revolutions to produce ensemble-averaged velocity and flow-angle distributions for the complete annulus in an angular direction.

To investigate rotating stall inception, total pressure probes were mounted upstream of the rotor, close to the casingwall. This setup was first proposed by Petermann (1961), who used a pneumatic total pressure probe with the head of the probe inclined by 90 degrees to its axis. Petermann aligned the probe to the circumferential direction against rotor rotation to detect rotating stall. In order to determine the transient behavior of the stall inception process, as well as its motion relative to the rotor, right from the beginning (Camp and Day, 1997), two unsteady total pressure probes (circumferential distance $\Delta \Theta=45^{\circ}$; one of them is shown in Figure 1) were applied. These probes, developed by Brodersen and Wulff (1992), use a high-frequency miniature pressure transducer (Kulite XCS062-5D) as probe head geometry. Phase-locked measurements (800 samples per rotor revolution) of the unsteady total pressure were recorded $\Delta z=-5$ and $-15 \mathrm{~mm}$ upstream of the rotor for various radial probe positions $r^{\prime}$ and probe angles $\varepsilon$. The available data storage was divided up into equal shares to save the pre- and post-stall history using the stall event itself as an internal trigger. Data recording and reduction procedures (averaging excepted) are the same as presented above for the hot-wire measurements.

\section{EXPERIMENTAL RESULTS AND DISCUSSION}

\section{Stage Characteristics}

The compressor's overall performance is presented in Figure 2, which shows (1) the nondimensional static-to-static pressure rise $\psi_{S S} ;(2)$ the nondimensional inlet-stagnation to outlet-static pressure rise $\psi_{T S}$, derived from (1); and (3) the efficiency $\eta$ plotted against the flow coefficient $\varphi$. The $\psi_{T S}$ representation of the compressor pressure rise capability shows that the theoretical condition $d \psi_{T S} / d \varphi=0$ for instability to occur is fulfilled exactly (Stenning, 1980). The instability point is at $\varphi=0.41$ and the best efficiency point at $\varphi=0.55$.

The thickness of the casingwall boundary layer is $\delta=6 \mathrm{~mm}$ at about $60 \%$ chord upstream of the rotor and the corresponding integral parameters are $\delta^{*}=0.75 \mathrm{~mm}, \Theta=0.58 \mathrm{~mm}$, and $H=1.3$. 


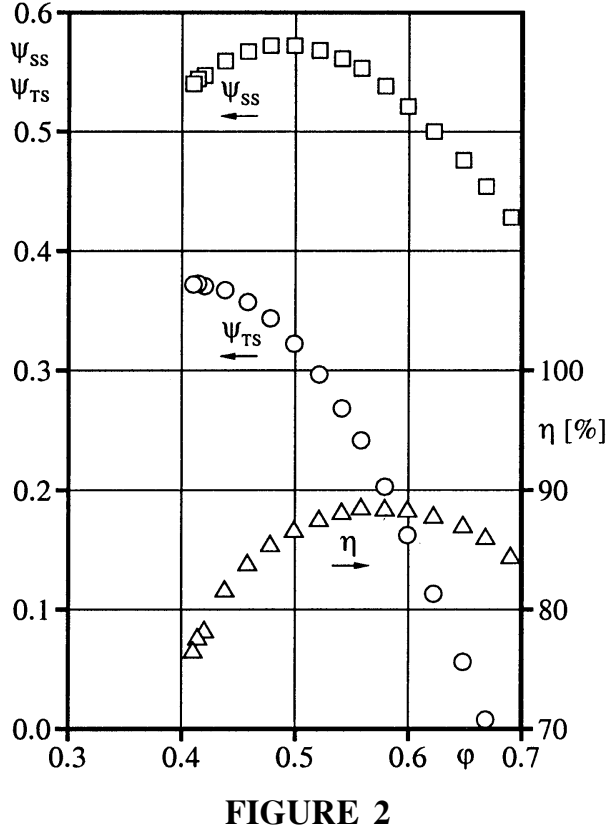

Compressor performance characteristics.

\section{Steady Casingwall Flow Phenomena}

The stator throughflow is determined by the stator inlet or rotor outlet flow, which in turn depends on the rotor throughflow. The rotor throughflow-especially the rotor overtip casingwall flow-has previously been investigated in some detail utilizing an oil flow technique and a periodic multisampling and averaging technique to produce oil flow pictures and ensemble-averaged casingwall pressure distributions, respectively. Oil flow pictures and pressure distributions have been carefully analyzed with the following, more important results (see Saathoff, 2001; Saathoff and Stark, 2001):

1. The rotor casing flow separates along a (black) circumferential separation line at all flow rates (See Figures 3 and 6, left frames, rotor section [Saathoff, 2001]). The position of the separation line is next to the trailing edge line at the higher flow rates and moves upstream with decreasing flow rate. At flow rates close to stall, the separation line is close to the leading edge.

2. The separation line occurs where the incoming casing boundary layer separates due to the blockage effect of a tip clearance flow that is axially backward-directed. The blockage effect increases with decreasing flow rate.

3. The axially backward-directed tip clearance flow is confined between the momentary separation line and the (almost white) trailing edge line, which is, topologically, an attachment line.

4. At high and medium flow rates the casingwall pressure distributions show a well-defined clearance vortex inside and outside the rotor. For lower flow rates $(\varphi<0.5)$, however, the clearance vortex is enclosed inside the rotor passage.

Saathoff (2001) used conventional pneumatic pressure probes to measure the mean flow conditions upstream of and downstream from the rotor as well as downstream from the stator. In the present investigation two hot-wire probes were applied to determine (1) the local properties of the flow depending on $r$ and $\Theta$ as spatial variables and (2) the circumferentially averaged flow properties, with $r$ as the remaining variable. In general, the resulting mean velocity and mean angle distributions agree quite well, though there are some minor differences near the hub and the casing (Rohdenburg and Kosyna, 2001).

The mean angle distributions $\beta_{2}(r)$ of the absolute rotor outlet flow (stator inlet flow), determined by the hot-wire probes, were measured for a number of flow rates along the stage characteristic. Subsequent analysis showed that the incidence angles for the stator tip were much higher than had been expected, especially at part-load conditions (Table 1).

Another important aspect of $\varphi=0.41$ is the sinusoidal variation of the mean stator inlet angle $\beta_{2}$ in circumferential direction with decreasing amplitude $\left(\hat{\beta}_{2}=8.3,7.4\right.$, and 5.9 $)$ and

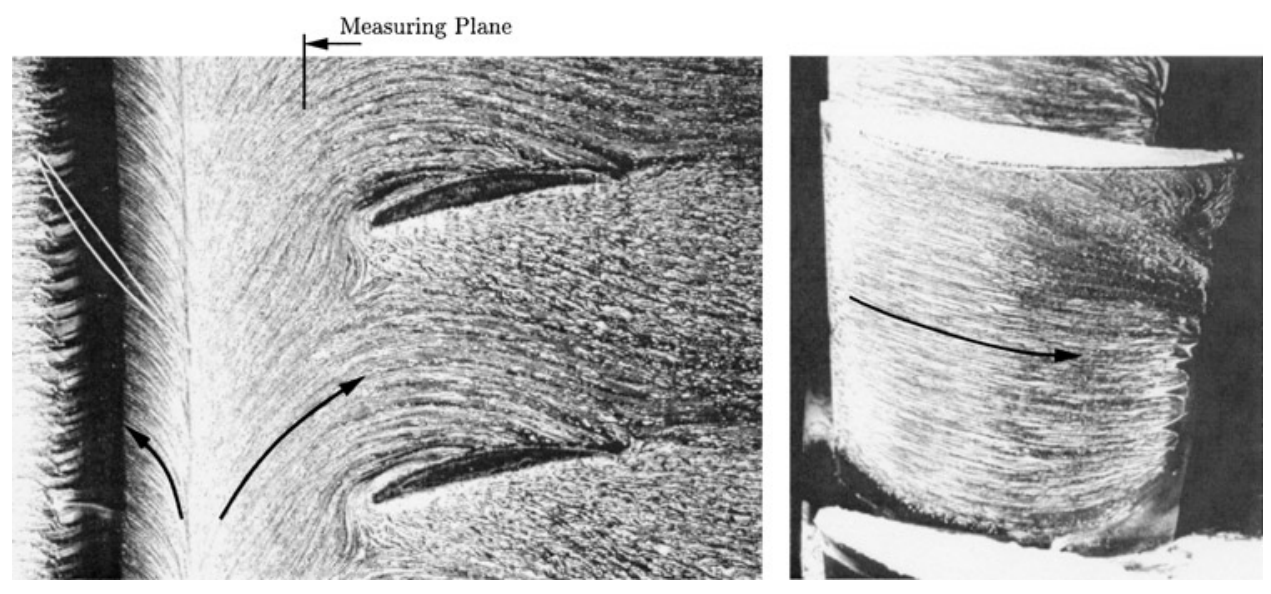

FIGURE 3

Compressor casing and stator suction side oil flow picture, $\varphi=0.60$. 
TABLE 1

Stator Tip and Hub Inlet Flow and Incidence Angles

\begin{tabular}{lcccc}
\hline & $\beta_{2, \text { tip }}$ & $i_{2, t i p}$ & $\beta_{2, \text { hub }}$ & $i_{2, \text { hub }}$ \\
\hline $\begin{array}{c}\text { Design, 2D } \\
(\varphi=0.60)\end{array}$ & $26.1^{\circ}$ & $-1.52^{\circ}$ & $41.7^{\circ}$ & $+2.08^{\circ}$ \\
$\begin{array}{c}\text { Design, exp. } \\
(\varphi=0.60)\end{array}$ & $40.2^{\circ}$ & $+12.56^{\circ}$ & $46.1^{\circ}$ & $+6.47^{\circ}$ \\
$\begin{array}{c}\text { Off design, exp. } \\
(\varphi=0.41)\end{array}$ & $69.3^{\circ}$ & $+41.66^{\circ}$ & $63.5^{\circ}$ & $+23.87^{\circ}$ \\
& & & & \\
\hline
\end{tabular}

increasing mean value $\left(\beta_{2}=59.0,64.3\right.$, and $\left.69.3^{\circ}\right)$ in radial direction $(r=191,195$, and $199 \mathrm{~mm})$.

Without any three-dimensional corrections, in the design process, the usual differences between the design incidence angles and the measured (design and off-design) incidence angles were expected. This assumption turned out to be correct for the stator hub but not for the stator tip section (see Table 1). For the stator tip, the measured incidence angles were much higher than expected.

Figures 3 through 8 show selected results of the present investigation for $\varphi=0.60$, the design flow rate, and $\varphi=0.41$, the last stable operating point before stall, respectively. Figures 3 and 6 are oil flow pictures, each showing (1) the stage casingwall flow and (2) the blade suction side flow of one of the stator blades; Figures 4 and 7 present the axial velocity component; and Figures 5 and 8 show the stator inlet angle obtained by hot-wire anemometry in contour form.

The results of visualization tests (time mean portraits of the endwall flow) are shown in Figures 3 and 6 for the flow rates $\varphi=0.60$ and 0.41, respectively. In agreement with Saathoff (2001), the rotor flow is seen to be axially forward-directed, then backward and again forward-directed with a (black) upstream moving separation and an (almost white) stationary attachment line between the different sections. What cannot be seen in the oil flow pictures but, however, is known from Saathoff (2001) is that at high and medium flow rates, a well defined tip clearance vortex exists, inside and outside the rotor, and that at flow rates between maximum pressure rise and stall, the clearance vortex is enclosed in a separation bubble inside the rotor. The separation bubble develops on the inner casingwall and begins and ends with a separation and attachment line, respectively.

The exact shape and radial depth of the separation bubble has not been determined as yet. But from Saathoff (2001) we know that for $\varphi<0.50$ (maximum pressure rise) the separation bubble considerably grows in the radial direction, resulting in substantial endwall blockage, where blockage means a reduction in effective freestream or core flow area. This is confirmed by the present results and may be seen by comparing Figures 4 and 7.

Figures 4 and 7 are contour plots (with, unfortunately, different contour legends) of the axial velocity $W_{2 z}$ (in $\mathrm{m} / \mathrm{s}$ ) using different colors for different velocity levels. When comparing them with each other, the first thing to be observed is that the radial depth of the low-velocity band along the casing increases dramatically when the flow rate decreases from $\varphi=0.60$ to $\varphi=0.41$. The second interesting aspect is that, at the same time, there is a noticeable decrease in the velocity level. This causes unexpected high inlet and incidence angles for $\varphi=0.41$, clearly to be seen when Figure 6 is compared to Figure 3, and when Figure 8 is compared to Figure 5 (where, again, the contour legends are not identical).

The contours in Figure 5 indicate a single vortex, embedded in an endwall flow between rotor and stator. The conclusion is that for $\varphi=0.60$, a tip clearance vortex exists inside and outside the rotor. In Figure 8, for $\varphi=0.41$ there is no indication of a tip clearance vortex, which means that a possibly initiated clearance vortex degenerates before reaching the measuring plane. This is already known to be true and has been described by Saathoff (2001), who also mentioned that for $\varphi=0.41$, the tip clearance
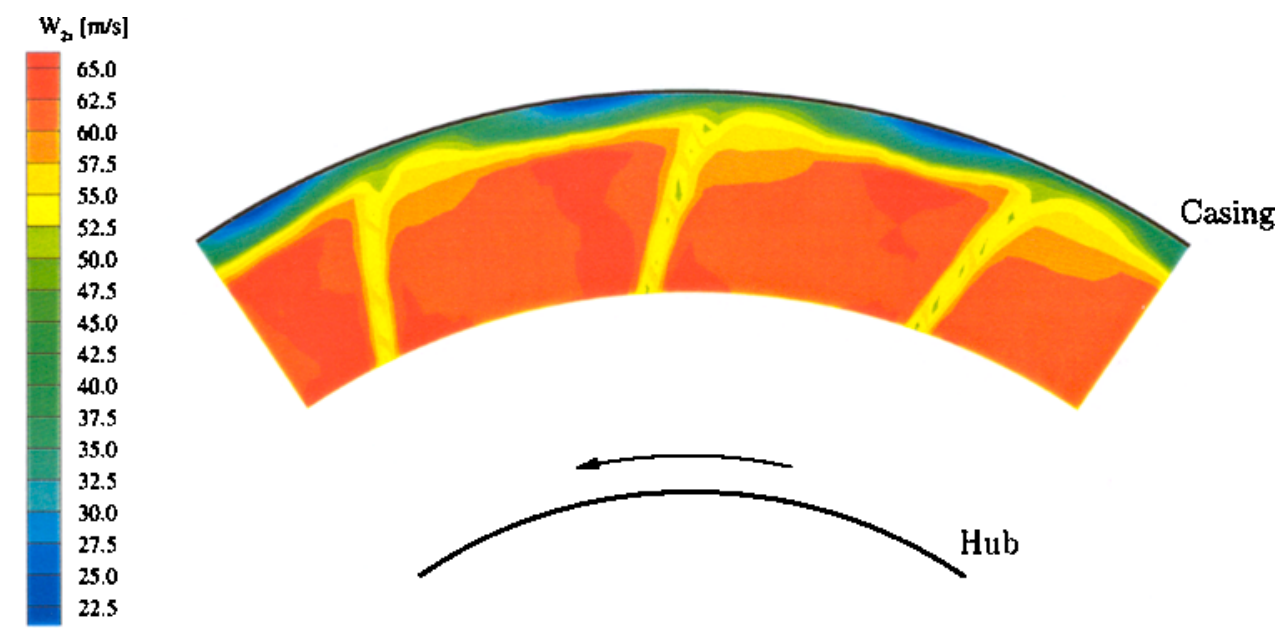

FIGURE 4

Rotor wake measurements, $\varphi=0.60$. Ensemble-averaged axial velocity $W_{2 z}$. 


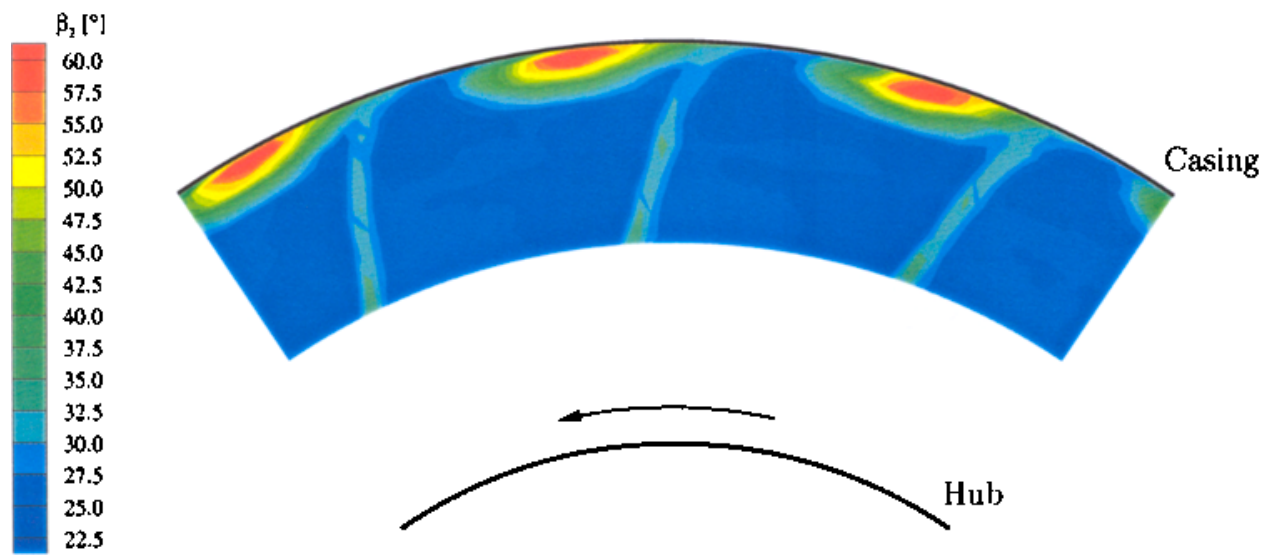

FIGURE 5

Rotor wake measurements, $\varphi=0.60$. Ensemble-averaged absolute flow angle $\beta_{2}$.

vortex was found (using casing wall pressure distributions) to have already degenerated within the rotor.

Without a clearance at the hub and tip, the stator part-load performance has often been described as being dominated by a severe hub corner stall with zero or only moderate tip corner stall (Joslyn and Dring, 1985; Poensgen, 1991). In the present investigation things are vice-versa. The dominant feature of the stator flow seen in Figure 6 (left and right) is an extreme suction surface tip corner stall in combination with a modest hub corner stall.

In Figure 3 for $\varphi=0.60$, that is, the design flow rate, the stator tip endwall flow shows classical secondary flow with a separation line surrounding each profile and an overturning of the main endwall flow. The corresponding suction surface flow is almost two-dimensional, with a mild hub and tip corner stall. As the flow rate decreases, the excessive high-inlet angles cause an extreme tip corner stall to develop, which becomes the controlling feature of the stator flow. In Figure 6, for $\varphi=0.41$, the last stable operating point before stall, the suction surface flow near the tip is seen to separate directly at the blade's leading edge and then to form a vortex with a three-dimensionally curved axis and a highly complicated, induced velocity field. Behind the vortex and on the suction surface some of the flow goes forward toward the leading edge, turns radially inward, and then moves aft to become part of a vortex, with its focus on the suction surface. The characteristic structure of the endwall oil flow picture is believed to be due to the highly twisted and fluctuating inlet flow.

\section{Unsteady Casingwall Flow Phenomena}

As discussed in the preceding section for the last stable operating point of the compressor $(\varphi=0.41)$, an axially backwarddirected tip clearance flow close to the casing extends over the entire axial chord of the rotor. The separation line between incoming flow and axial reverse flow has reached the leading edge plane of the rotor (see Figure 6, left frame). Further throttling of the compressor leads to rotating stall, with the separation line jumping far in front of the rotor, which considerably extends the axial reverse flow region (Saathoff, 2001).
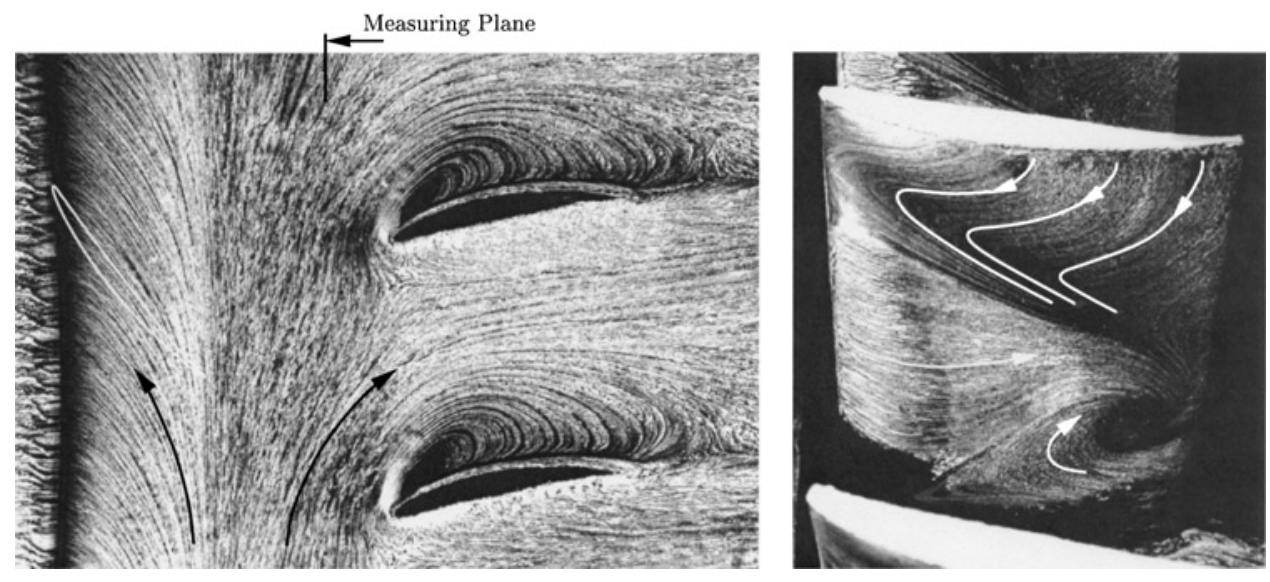

FIGURE 6

Compressor casing and stator suction side oil flow picture, $\varphi=0.41$. 


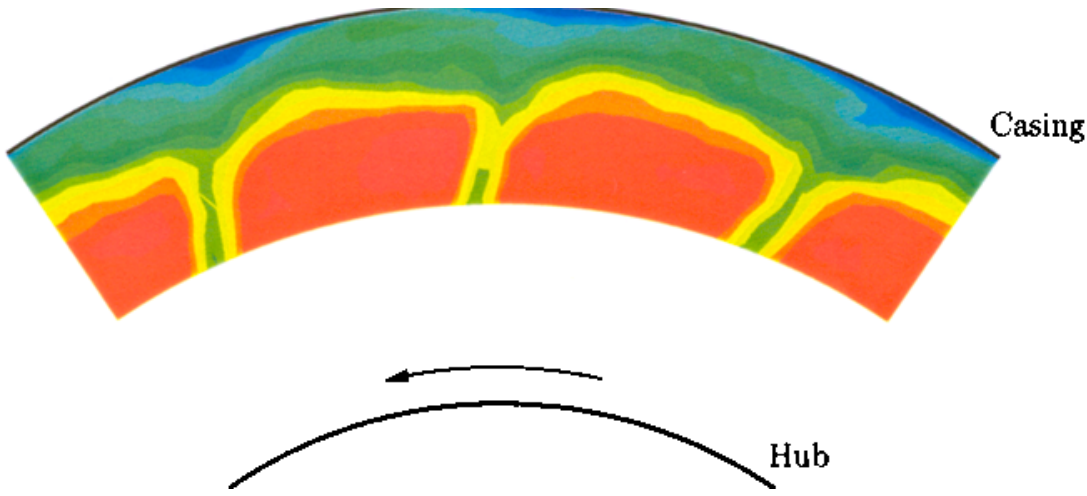

FIGURE 7

Rotor wake measurements, $\varphi=0.41$. Ensemble-averaged axial velocity $W_{2 z}$.

To enhance understanding of the rotor's relative flow close to the casingwall, this flow was simulated in a 2:1 linear cascade model of the rotor tip section, including tip clearance between the blades and one endwall (Saathoff, 2001). One selected result of this investigation, an oil flow picture of the cascade endwall for an inlet flow angle of $\beta_{i n}=64$ degrees, corresponds to a stall operating point is shown in Figure 9. The main flow features to be seen are the clearance flow and vortex. The tip clearance vortex (a), which is identifiable by the S-shaped shear stress lines, starting at the rollup point, which is close to the leading edge of the blade, begins to develop and may be traced up to the $65 \%$ chord position, where (1) the S-shape of the shear stress lines suddenly disappears and (2) the cross section of the vortex rapidly expands-both of which are indications of an abrupt degeneration of the clearance vortex. Downstream from the vortex, the endwall flow crosses the passage diagonally, then contracts, and finally spills forward ahead of the next blade and from there into the next passage along the row. Together with the clearance vortex, the spilled clearance flow acts as a flow obstruction causing the incoming endwall boundary layer to separate and then to pass around the flow barrier.
Spill-forward in compressors has previously been investigated numerically by McDougall (1988), Goto and Okamoto (1997) (steady analysis), and by Hah and colleagues (1999) (steady and unsteady analysis), and experimentally by Cumpsty (1989), Silkowski (1995), and Dobat and colleagues (2001). Cumpsty (1989) measured the characteristics of the endwall boundary layer upstream of a rotor operated with an axially skewed slot casing treatment over part of the circumference.

According to Cumpsty, the spilled endwall flow builds up circumferentially in an unsteady process, resulting, locally, in very high inlet blockage and normally (i.e., without treatment) in stall. Hah and colleagues (1999) calculated the time history of an isolated rotor's relative flow at stall inception. Results were published in a sequence of four successive pictures showing the instantaneous velocity vectors on an axisymmetrical surface of revolution between the rotor tip and the casing. Figure 10 is the first of these pictures, reproduced from Hah and colleagues (1999). Although there are differences between the experimental, steady-state clearance flow in a compressor cascade (Figure 9) and the numerical, unsteady clearance flow in a compressor rotor (Figure 10), a remarkable similarity in the endwall flows can be found.

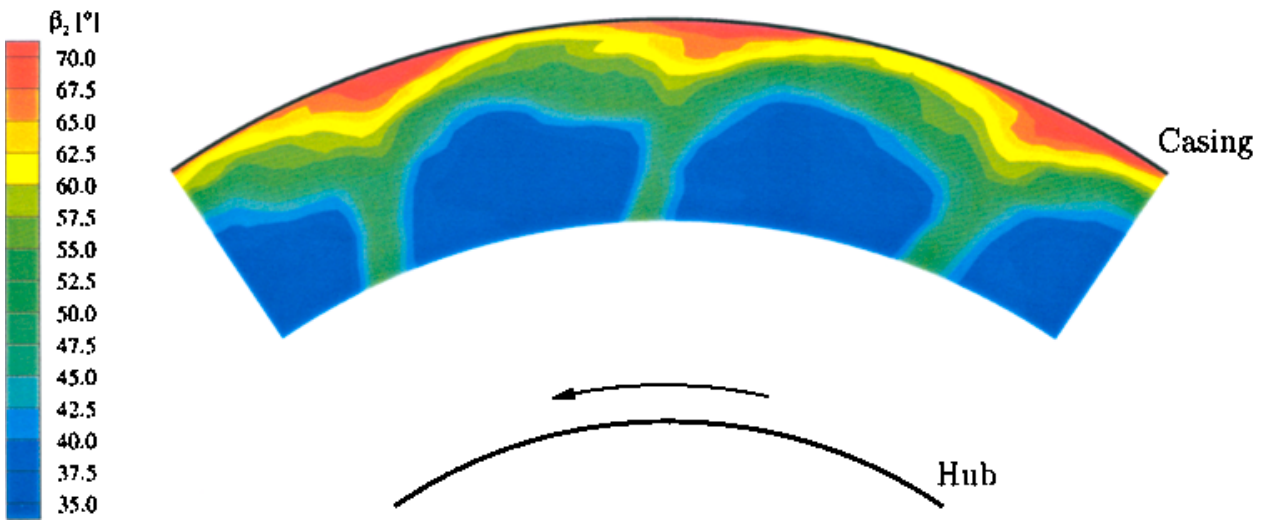

FIGURE 8

Rotor wake measurements, $\varphi=0.41$. Ensemble-averaged absolute flow angle $\beta_{2}$. 


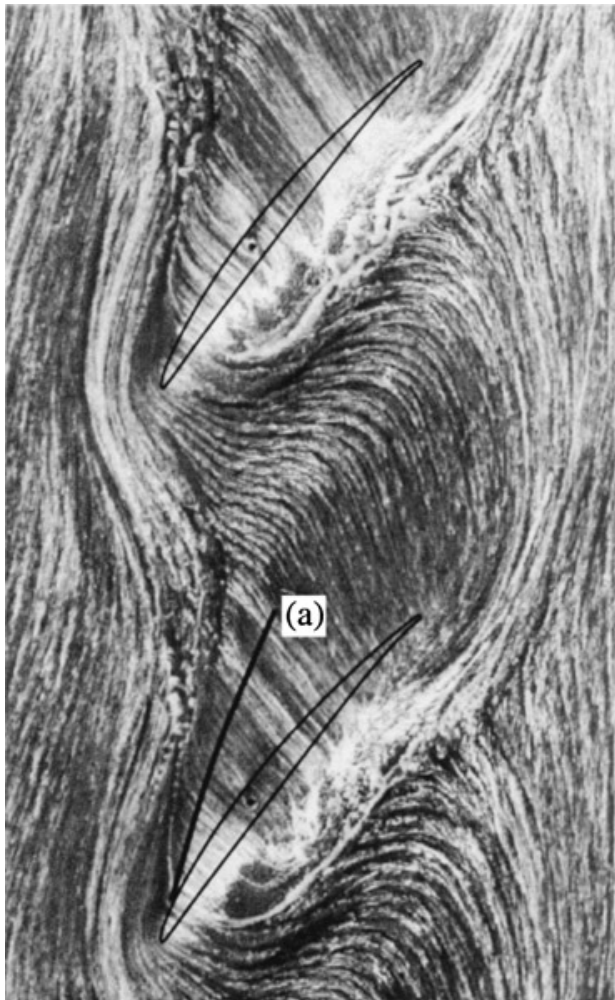

FIGURE 9

Cascade endwall oil flow picture for $\beta_{\text {in }}=64$ degrees; the trajectory of the clearance vortex is indicated by (a).

The results presented so far show that rotating stall inception may be initiated by an axially backward-directed tip clearance flow that spills forward ahead of the rotor. Spill-forward is an unsteady process in compressors, finally leading to rotating stall (compare Hah et al., 1999). To determine the transient behavior of the stall inception process in the present compressor, measurements applying two unsteady total pressure probes upstream of the rotor were conducted. A selected result of these measurements (see also Dobat et al., 2001), is shown in Figure 11. What can be seen are the contours of the unsteady total pressure measured by the two probes during rotating stall inception. Both probes were mounted $\Delta z=-5 \mathrm{~mm}$ upstream of the rotor with $\Delta r^{\prime}=2 \mathrm{~mm}$ distance from the casingwall and an angle of $\varepsilon=45$ degrees between the probe head and the machine axis (with the probe's head facing the rotor inlet plane; see Figure 11). The total pressure contours presented in Figure 11 were reshifted during data reduction to compensate for the circumferential distance $\Delta \Theta=45$ degrees of the two probes achieving the same geometric position in rotor coordinates for the measured data.

During stable compressor operation, the total pressure contours are formed by the upstream effect of the rotor blades. During each rotor revolution, 16 blades can be identified passing the probes. During the 38th rotor revolution (with each probe, the unsteady total pressure was measured for 80 rotor revolutions), both probes detect the first disturbance of the total pressure up-

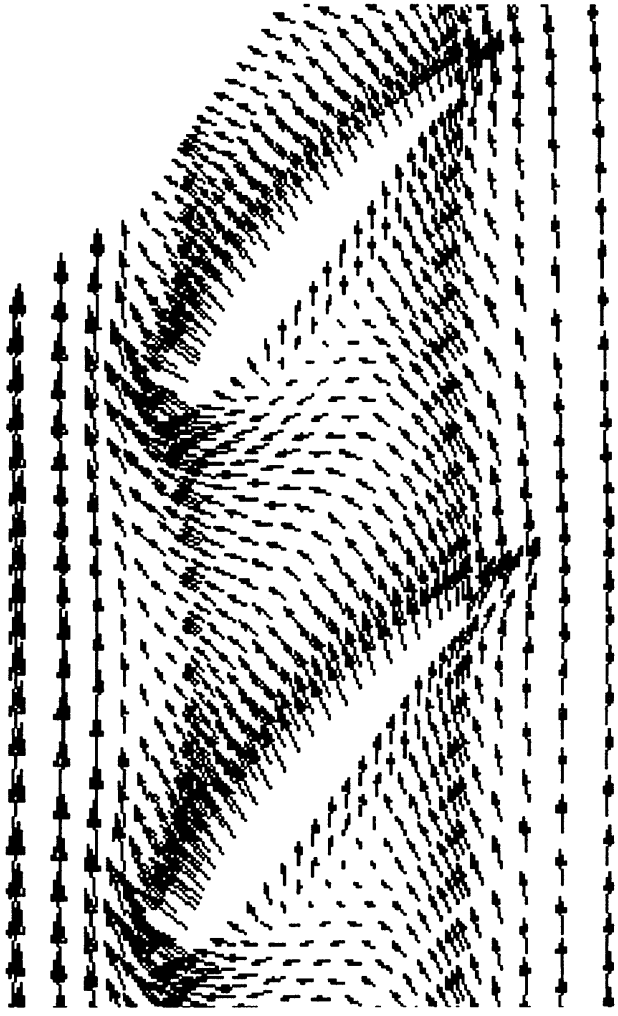

FIGURE 10

Instantaneous relative velocity vectors near the tip of a low-speed compressor rotor at stall inception, as calculated by Hah and colleagues (1999).

stream of the rotor. The disturbance is shaped like a spike-a distinct pressure or suction peak of small circumferential extention. The first experimental evidence of this phenomenon was given by Day (1993), who attributed the occurence of spikes to local flow separations in the tip region of the rotor blading (see also Camp and Day (1997)).

Starting with the spikes discussed above, both measured contours in each case show similar disturbances of the total pressure increasing in size (circumferential extention) until, after lower than 10 rotor revolutions, a steady state is again reached (see Figure 11). Thus, it may be concluded that in the present case one local flow phenomenon grows into a fully developed stall cell. The distance in time between the first and second appearances of a total pressure disturbance is about 1.5 rotor revolutions; hence, the corresponding flow phenomenon is moving with about $60 \%$ rotor speed against rotor rotation. Increasing in size, the flow phenomenon slows down until finally, the fully developed stall cell moves with $45 \%$ rotor speed against rotor rotation. The relative motion between the flow phenomenon and the rotor has an effect on the measurement from the absolute system. It takes, for example, one rotor revolution to sense a fully developed stall cell. Considering its motion relative to the rotor, however, the circumferential extention turns out to be about one half of the rotor's circumference. During acceleration or deceleration of a 


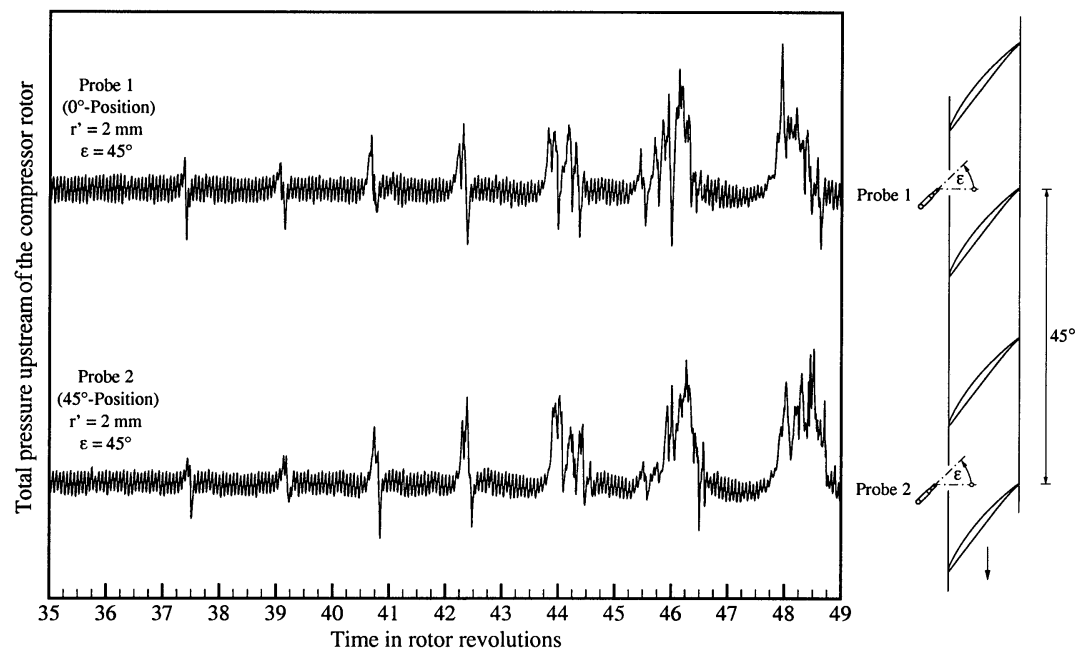

FIGURE 11

Unsteady total pressure upstream of the rotor during rotating stall inception; measurement with two pitot probes $(z=-5 \mathrm{~mm}$; $r^{\prime}=2 \mathrm{~mm} ; \varepsilon=45$ degrees).

flow phenomenon moving relative to the rotor, measurements from the absolute system allow only an approximation of velocity and circumferential extention, but they are more accurate the closer the probes are mounted at the casing.

In order to analyze the recorded data with regard to the appearance of spill-forward, the first spike determined by probe 1 has been enlarged in Figure 12, which shows the unsteady total pressure measured for one half of a rotor revolution. Each blade passing the probe has been indicated by a vertical line. The spike seen is characterized by a pressure peak just before a blade passes the probe, followed by a distinct suction peak along the succeeding blade's passage. The relevant flow for a total pressure probe mounted at the compressor casing is the absolute flow. Hence, a total pressure peak is caused by an absolute flow aligned with the probe's head, whereas a suction peak may be attributed to a mis-

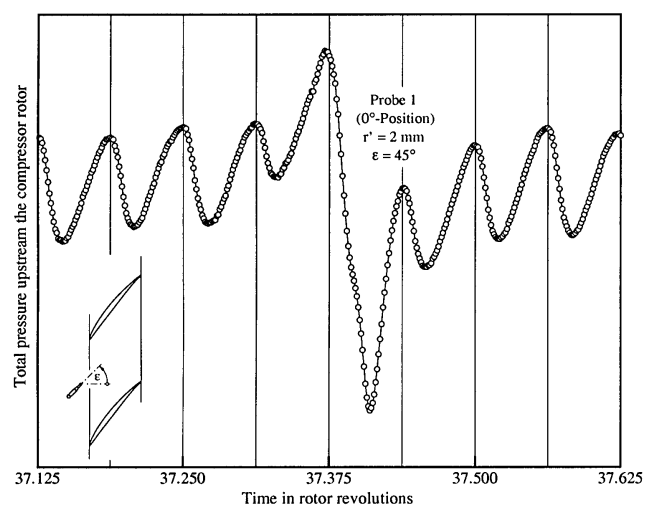

FIGURE 12

Unsteady total pressure upstream of the rotor during stall inception; first spike at probe $1\left(z=-5 \mathrm{~mm} ; r^{\prime}=2 \mathrm{~mm}\right.$; $\varepsilon=45$ degrees $)$. alignment between the probe head and the absolute flow direction. The absolute velocity, which corresponds to the relative velocity determined for spill-forward (compare the cascade result, Figure 9, as well as the result of the unsteady numerical calculation, Figure 10) is aligned with the probe's head, thus producing a pressure peak just before the next rotor blade passes the probe (see also Silkowski, 1995). The fluid spilling forward ahead of the rotor is immediately turned into the direction of the main flow, which is misaligned with the probe's head, producing a severe suction peak in the total pressure contour (see Figure 12). Based on this analysis of the first spike detected during rotating stall inception, it may be concluded that spill-forward of the tip clearance flow ahead of the rotor can initiate rotating stall.

\section{SUMMARY AND CONCLUSIONS}

An oil flow technique to visualize the boundary layer development and high-frequency sensors to measure ensemble-averaged velocity and flow-angle distributions downstream from as well as unsteady total pressure distributions upstream of the rotor have been utilized to investigate the casingwall flow phenomena in a single-stage, axial-flow, low-speed compressor. The results have been carefully analyzed and the following conclusions have been drawn:

1. The rotor casing flow separates along a circumferential separation line at all flow rates due to the blockage effect of a tip clearance flow that is axially backward-directed. The separation line moves upstream with a decreasing flow rate, reaching the leading-edge line of the rotor at flow rates close to stall.

2. At high and medium flow rates, a well-defined clearance vortex exists inside and outside of the rotor blade's passage. At part-load conditions, however, the clearance vortex is 
enclosed inside the rotor passage, considerably increasing endwall blockage.

3. The increased rotor blockage at part-load conditions leads to highly increased stator inlet-flow angles near the casingwall, causing severe leading-edge separation of the stator blade's boundary layer.

4. Exceeding the stability limit, the experimental results show unsteady spillage of the rotor endwall flow ahead of the next blade and from there into the next passage along the row.

\section{NOMENCLATURE}

a Rotor/stator gap

$D_{o} \quad$ Outer diameter

$H \quad$ Shape factor

$i_{2} \quad$ Stator incidence angle

$l \quad$ Chord length

$n \quad$ Rotational speed

$r^{\prime} \quad$ Radial distance from casing, see Figure 1

Re Reynolds number

$s \quad$ Tip clearance

$W_{2 z} \quad$ Axial velocity at stator inlet

$z, r, \Theta \quad$ Compressor coordinate system

$\beta_{\text {in }} \quad$ Cascade inlet flow angle

$\beta_{2} \quad$ Stator inlet flow angle

$\hat{\beta}_{2} \quad$ Amplitude of $\beta_{2}$-variation

$\delta \quad$ Boundary layer thickness

$\delta^{*} \quad$ Displacement thickness

$\varepsilon \quad$ Probe angle, see Figure 11

$\eta \quad$ Efficiency

$\Theta \quad$ Momentum thickness

$v \quad$ Hub to tip ratio

$\varphi \quad$ Flow coefficient

$\psi \quad$ Pressure rise coefficient

\section{Subscripts}

$S S, T S \quad$ Static to static, total to static

tip, hub Tip, hub section

\section{REFERENCES}

Brodersen, S., and Wulff, D. 1992. Measurements of the pressure and velocity distribution in low-speed turbomachinery by means of high- frequency pressure transducers. ASME Journal of Turbomachinery 114:100-107.

Camp, T. R., and Day, I. J. 1997. A study of spike and modal stall phenomena in a low-speed axial compressor. ASME Journal of Turbomachinery 120:393-401.

Cumpsty, N. A. 1989. Part-circumference casing treatment and the effect on compressor stall. ASME Paper 89-GT-312.

Day, I. J. 1993. Stall inception in axial flow compressors. ASME Journal of Turbomachinery 115:1-9.

Dobat, A., Saathoff, H., and Wulff, D. 2001. Experimentelle Untersuchungen zur Entstehung von Rotating Stall in Axialventilatoren. VDI-Berichte 1591:345-360.

Goto, A., and Okamoto, H. 1997. Casing treatment with air blowing in an axial-flow fan. Proceedings of the JSME Centennial Grand Congress, International Conference on Fluid Engineering, 11151120. Tokyo, Japan.

Hah, C., Schulze, R., Wagner, S., and Hennecke, D. K. 1999. Numerical and experimental study for short wave length stall inception in a lowspeed axial compressor. Paper AIAA 99-IS-033 presented at the 14th ISABE, Firenze, Italy.

Joslyn, H. D., and Dring, R. P. 1985. Axial compressor stator aerodynamics. ASME Journal of Engineering for Gas Turbines and Power 107:485-493.

McDougall, N. M. 1988. Stall inception in axial compressors (PhD diss, U. Cambridge).

Petermann, H. 1961. Sicherheitssteuereinrichtung gegen ein längeres Arbeiten von Axialverdichtern im Abreißgebiet. Stahl und Eisen 81:589-593.

Poensgen, C. A. 1991. Experimentelle Untersuchung der Strömung in einer Unterschall-Axialverdichterstufe bei hoher Drosselung und im Rotating Stall. Aachen (PhD diss, U. Aachen).

Rohdenburg, M., and Kosyna, G. 2001. Experimentelle Bestimmung der Grenzschichtparameter von Axial ventilatorstufen als Basis für Kennfeldberechnungen. VDI-Berichte 1591:361376.

Saathoff, H. 2001. Rotor-Spaltströmungen in Axial verdichtern (PhD diss, TU Braunschweig).

Saathoff, H., and Stark, U. 2001. Tip clearance flow in a low-speed compressor and cascade. Proceedings of the 4th European Conference on Turbomachinery: Fluid Dynamics and Thermodynamics, 81-91. Firenze, Italy: Servizi Grafici Editoriali, Padova.

Silkowski, P. D. 1995. Measurements of rotor stalling in a matched and a mismatched multistage compressor. MIT Gas Turbine Laboratory Report \#221: MIT Gas Turbine Laboratory.

Stenning, A. H. 1980. Rotating stall and surge. ASME Journal of Fluids Engineering 102:14-20. 

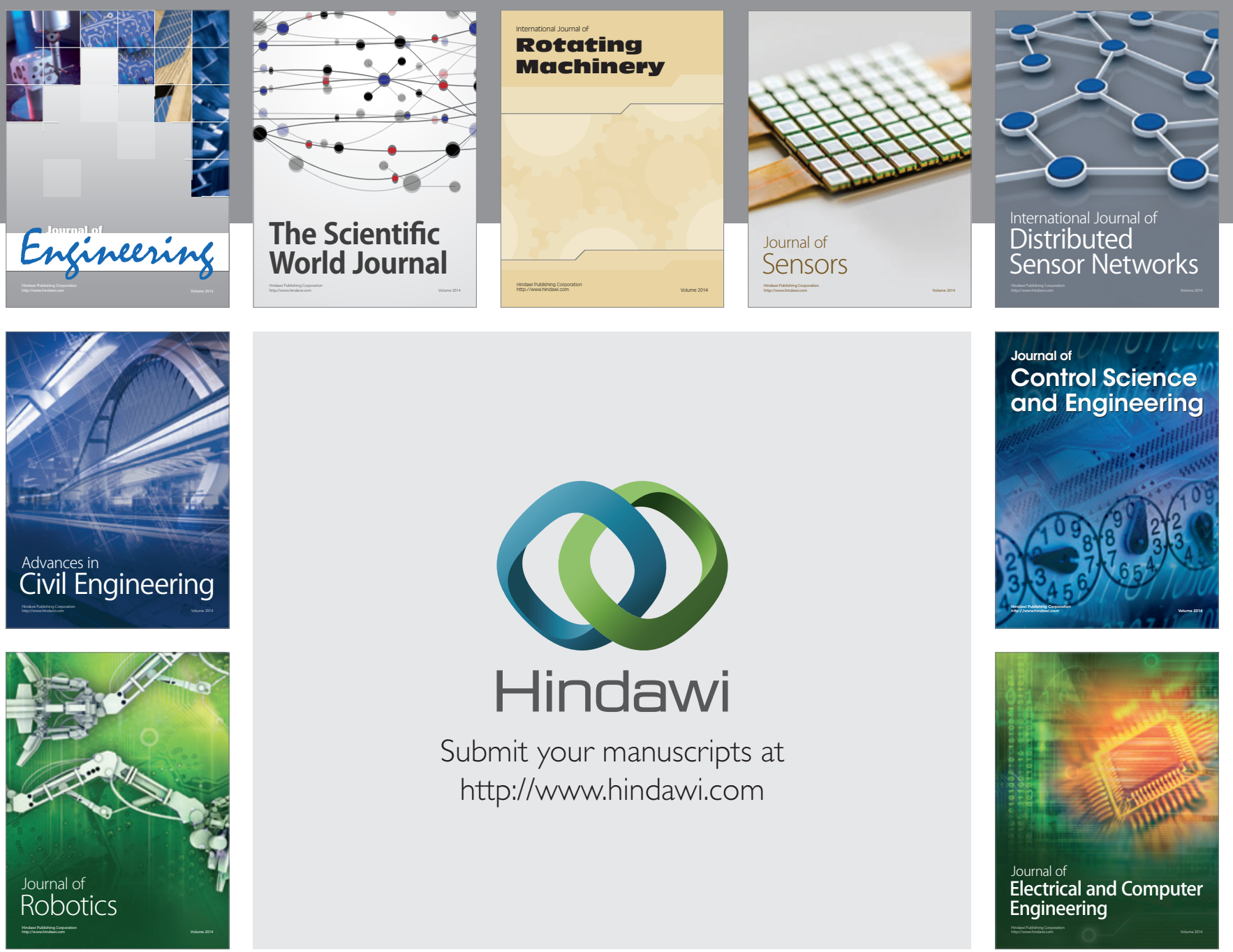

Submit your manuscripts at

http://www.hindawi.com
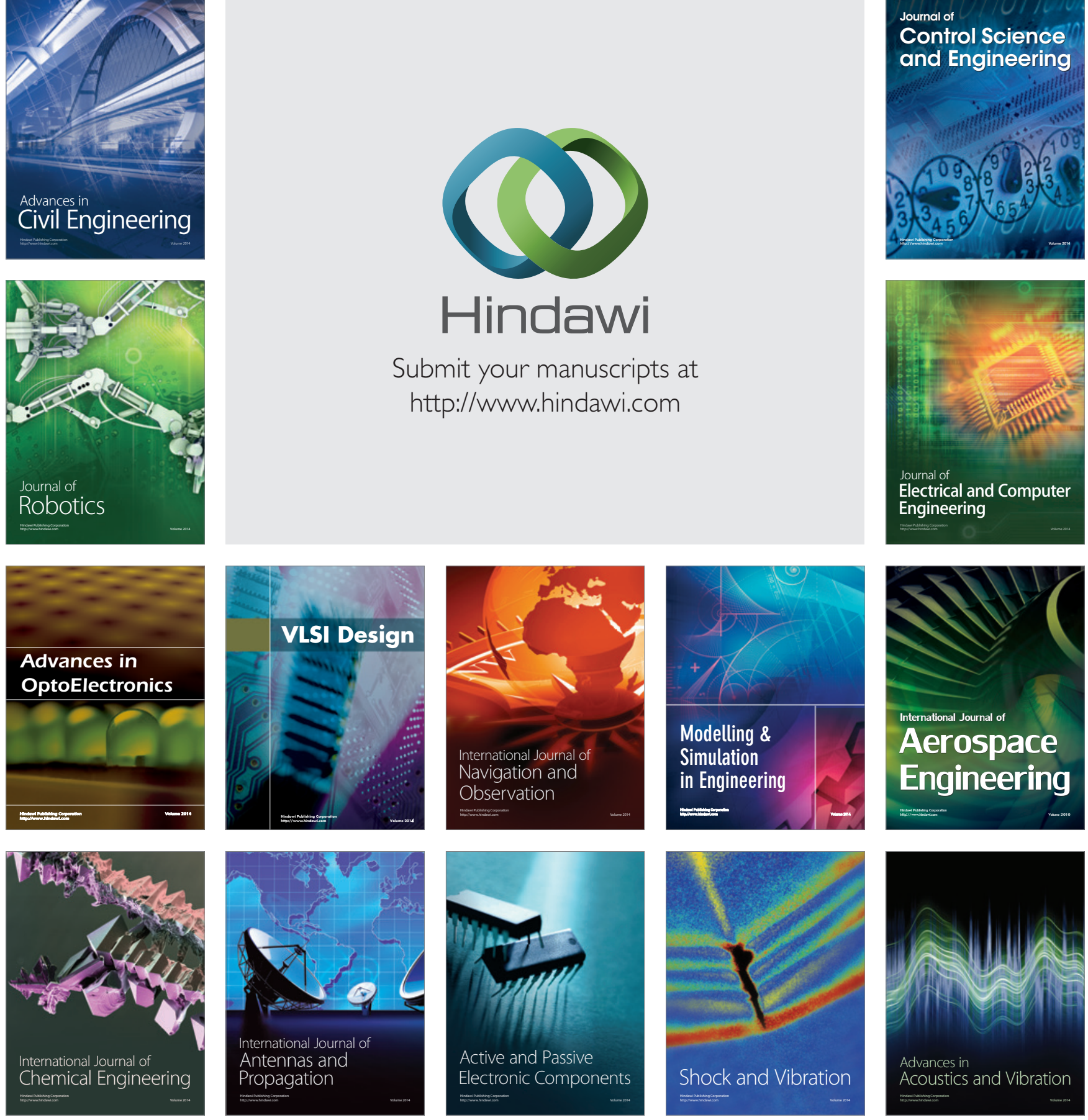